\title{
ASPECTOS FÍSICOS, QUÍMICOS E MICROBIOLÓGICOS DE LATOSSOLO VERMELHO-AMARELO TRATADO COM DOSES CUMULATIVAS DE ESTERCO DE GRANJA
}

\author{
JAIRO R. JIMÉNEZ-RUEDA*, SÂMIA M.T. TORNISIELO**, IVANA F. BARBOSA**, \\ MARIA T. BENATT1*** ANGELA N. UEMURA**
}

\begin{abstract}
PHYSICAL, CHEMICAL AND MICROBIOLOGICAL ASPECTS OF A RED-YELLOWISH LATOSSOL TREATED WITH CUMULATIVE DOSES OF CHICKEN MANURE. About 5 tons ha-1 yr-1 of chicken manure was applied during 17 years to a red-yellowish latossol from sediments of Rio Claro Formation with the purpose of evaluating the effects of the applications on their chemical, physical and microbial properties. The suitable concentration of chemical elements for the development of any culture were changed due to modifications on chemical properties. The physical properties also changed, mainly structural stability; it was good for applications until 13 years, but was bad afterwards. This showed little effect of the organic matter and a tendency of thickening of the superficial cover of the soil, which obstructs the penetration of roots and water, increasing the vulnerability to erosion. It was also observed that the organic matter contents increase contributing for the regulation of nutrientes, water, temperature and improvement of edaphical conditions.
\end{abstract}

Keywords: Red-yellowish latossol, chicken manure, structural stability, organic matter, vulnerability to erosion.

\begin{abstract}
RESUMO Aplicações da ordem de 5 t/ha/ano de estrume de frango foram feitas, durante 17 anos, em um latossolo vermelho-amarelo originário de sedimentos da Formação Rio Claro, com a finalidade de avaliar os efeitos de tais aplicações sobre as propriedades químicas, físicas e microbiológicas do referido solo. As concentrações dos elementos químicos apropriados para o desenvolvimento de qualquer cultura foram mudadas em função das modificações das propriedades químicas do solo. As propriedades físicas também mudaram, principalmente a estabilidade estrutural. Esta mostrou-se boa para aplicações até os 13 anos e ruim além desta idade. Isto indica pouco efeito da matéria orgânica e uma tendência ao adensamento dos volumes superficiais do solo, o que dificulta a penetração do sistema radicular e de água, aumentando a vulnerabilidade à erosão. Também foi observado que os conteúdos de matéria orgânica aumentaram, contribuindo para a regulação de nutrientes, água, temperatura e melhoria das condições edáficas.
\end{abstract}

Palavras-chaves: Latossolo vermelho-amarelo, estéreo de frango, instabilidade estrutural, matéria orgânica, vulnerabilidade a erosão.

INTRODUÇÃO A introdução de matéria orgânica pode causar aumento da comunidade microbiana, melhoria na estrutura e fertilidade do solo. A produtividade do solo baseia-se na presença de matéria orgânica em decomposição ou humificada (Hénin et al. 1976).

O estrume animal é comumente utilizado como fertilizante nas lavouras, favorecendo a bioestrutura de solo, com aumento da agregação do solo e proporcionando melhor crescimento vegetal (Primavesi 1980, Kiehl 1985).

A introdução do estéreo rico em matéria orgânica pode mudar e/ou adequar as propriedades do solo, como a cor, textura, estrutura e consistência e as características como porosidade, estabilidade, retenção de umidade e aeração (Malagón 1976).

$\mathrm{O}$ estéreo de frango tem sido utilizado por ser rico em nutrientes e não acarretar problemas com excesso de água encontrados nos demais estrumes animais. Além disso, a sua aplicação pode aumentar a fertilidade natural, a capacidade de troca catiônica, a reação, a soma das bases e a saturação do solo (Kiehl 1985).

A adição de alguns resíduos ricos em matéria orgânica tem acarretado acréscimo de determinados grupos, como as bactérias e fungos (Orjuela 1988) e de fungos filamentosos e de actinomicitos (Tauk 1990). A microbiota do solo atua como importante decompositor. A taxa de decomposição e conseqüentemente a quantidade disponível de nutrientes depende de fatores físicos, físico-quúnicos, químicos e biológicos do solo. Portanto, o estudo sobre a eficiência de aplicação de um resíduo ao solo deve compreender diferentes aspectos que abordam estes fatores. $\mathrm{O}$ manejo adequado do solo compreende aquele que não afeta drasticamente esses fatores (Primavesi 1980). A finalidade do preparo do solo consiste em deixá-lo em condições de receber sementes, além de controlar pragas e doenças e criar-lhe condições físicas adequadas (Centurion \& Demattê 1985).

$\mathrm{O}$ estudo dos fatores químicos, físicos, físico-químicos e biológicos serve como guia para o manejo racional de sua fertilidade. Pode-se reservar aos fertilizantes as funções de complementação e manutenção dos níveis de nutrientes no solo, tendo em vista a obtenção da produção agrícola máxima e economicamente viável (Orlando et al 1983).

MATERIAL E MÉTODOS A área em estudo situa-se no município de Rio Claro, distrito de Ajapi, Estado de São Paulo, e corresponde geomorfologicamente a província da Depressão Periférica, na zona do médio Tietê, sub-zona de Corumbataí (IPT 1981). Geologicamente, está dominada pela Formação Rio Claro, sedimentos policíclicos do final do Terciário e início

\footnotetext{
* Departamento de Geologia Aplicada, Instituto de Geociências e Ciências Exatas, Universidade Estadual Paulista, Rua 10, 2527, Caixa Postal 178, CEP 13500-970, Rio Claro, SP, Brasil

** Departamento de Ecologia, Instituto de Biociências, Universidade Estadual Paulista, Avenida 24-A, 1515, Caixa Postal 199, CEP 13500-970, Rio Claro, SP, Brasil
} 
do Quaternário. O clima da região está caracterizado como Subtropical, com médias anuais entre 18 e $24^{\circ} \mathrm{C}$, precipitação entre 1.000 e $2.000 \mathrm{~mm}$, apresentando uma termoperiodicidade que varia de 3 a $20^{\circ} \mathrm{C}$ (Almeida, 1983). O solo é do tipo Latossolo Vermelho-Amarelo.

Nessa área, tem sido aplicado estéreo de frango ( 5 ton/ ha/ano) em diferentes lotes, por um período variável de 0,0 / 2,5/6/ 13 e 17 anos. Para solo controle, tomou-se um lote sem aplicação desse resíduo, sob vegetação de cerrado. Os demais lotes apresentaram culturas de amoras, sendo que nos lotes de 2,57 6 e 13 anos de aplicação foram intercaladas culturas de milho em anos anteriores e, o lote de 17 anos manteve cultura de amoras durante todo período de aplicação de estéreo de frango.

$\mathrm{Na}$ área, foram descritos os perfis a partir de trincheiras abertas no centro de cada parcela. Essas tiveram, em média, 1,5 m de comprimento, 1,5 $\mathrm{m}$ de largura e 1,7 $\mathrm{m}$ de profundidade. Examinou-se o perfil, separou os horizontes e utilizandose o manual de descrição e coleta do solo no campo (Lemos \& Santos 1982).

De cada horizonte do solo, foram retiradas amostras que foram acondicionadas em sacos plásticos e submetidas às análises das propriedades que serão apresentadas a seguir.

1. A umidade relativa do solo foi determinada após deixar as amostras a $105^{\circ} \mathrm{C}$ até a obtenção do peso constante.

2. A granulometria foi caracterizada pela técnica descrita por Montenegro \& Malagón (1990). Os solos foram classificados em relação à granulometria utilizando-se o diagrama textural do USDA (Malagón 1976). A densidade aparente foi determinada a partir da técnica dos torrões (Hénin et al. 1976) e a densidade real através da técnica de picnômetros (Montenegro \& Malagón 1990), a partir do qual se calcula a porosidade total de acordo com Kaúrichev (1984) e interpretada de acordo com a seguinte escala:

\section{$\mathrm{PT}=\left(1-\frac{\mathrm{Da}}{\mathrm{DT}}\right) 100$}

\section{Ponsidade Total \% (PT)



\section{Apreciacta Qualitativa}

Porosidade excessiva Porosidade excelente Porosidade satisfatória Porosidade não satisfatória Porosidade muito baixa

3. Os limites de liquidez e de plasticidade foram caracterizados utilizando-se o método de Atterbeg (Stacanti et al 1981) e qualificados de acordo com Kaúrichev (1984), segundo o número de plasticidade:

$\begin{array}{ll}\text { Murito plástico } & >17 \\ \text { Plástico } & 17-7 \\ \text { Pouco plástico } & <7 \\ \text { Não-plástico } & 0\end{array}$

4. A estabilidade estrutural foi determinada pelos métodos seco e imersão de Sávrinov (Paula \& Coelho 1982, Kaúrichev 1984). Para a interpretação do índice K, que resulta da relação da porcentagem de agregados entre 0,25 e $2 \mathrm{~mm}$ e a soma das porcentagens de agregados $>2 \mathrm{~mm}$ e $<0,25 \mathrm{~mm}$, é possível dizer que o maior valor de $\mathrm{K}$ melhora a estabilidade estrutural (Kaúrichev 1984). Ao mesmo tempo, foram obtidas as médias geométricas dos diâmetros dos agregados e seu grau de agregação, e interpretados segundo a escala de degradação estrutural estabelecida por Malagón (1976) como segue:

\section{M.G. = Diametro superior (u) \\ 2Exp (\% acumulado - 50) \\ 100}

\section{Estado de agregação = \% agregados de cada um dos diametros - \% de cada uma das particulas \\ Grau de agregaçăo



5. A escala de degradação estrutural é definida em função da porcentagem de agregados menores de $0,5 \mathrm{~mm}$ em diâmetro: maior que $50 \%$ em agregados menores de $0,5 \mathrm{~mm}=$ muito alta degradação

entre $40-50 \%$ em agregados menores de $0,5 \mathrm{~mm}=$ alta degradação

entre $20-40 \%$ em agregados menores de $0,5 \mathrm{~mm}=$ média degradação

entre $10-20 \%$ em agregados menores de $0,5 \mathrm{~mm}=$ baixa degradação

menor que $10 \%$ em agregados menores de $0,5 \mathrm{~mm}=$ muito baixa degradação.

6. A análise química do solo compreendeu a determinação dos teores de cálcio, alumínio, magnésio, sódio, potássio, fósforo e hidrogênio pela metodologia adotada pela EMBRAPA (1979). Foi determinado o pH em KC1 0,1 N e em água, cujas diferenças forneceram os $\mathrm{pH}$.

7. A determinação de ácidos húmicos, ácidos fúlvicos, huminas e carbono extratável, foi realizada segundo Garavito (1979). A umidade do solo foi determinada em relação ao valor percentual hídrico sobre o peso seco (McLean \& Cook 1968).

8. Para a determinação do número de microorganismos, foram coletadas amostras (10 g) previamente peneiradas, utilizandose o procedimento citado por Tauk (1990). Assim, verifica-se o número de bactérias, actinomicetos e fungos filamentosos por grama de solo (peso seco). Foram determinadas as temperaturas do solo até 5 e $20 \mathrm{~cm}$ de profundidade, com termômetro de haste, durante a coleta das amostras.

RESULTADOS E DISCUSSÃO O Latossolo Vermelho-Amarelo, Tb, álico, A moderado, textura média, fase Cerrado (EMBRAPA 1988), foi utilizado como controle, para observar os efeitos causados pela aplicação de estéreo de frango ( 5 t/ha/ano), em tempos variados de 2,5/6/13 e 17 anos e sob cultura de amoreiras. Sendo caracterizados os perfis e tratamentos como AJ1 (2,5 anos); AJ2 (6 anos); AJ3 (13 anos); AJ4 (17 anos) e AJ5, (solo controle). Estes apresentam propriedades físicas, químicas e morfológicas típicas de latossolos de acordo com Vieira \& Vieira (1983) e Camargo et al (1987) (Tab. 1).

Esta caracterização mostra que os horizontes A subdivididos em Ap e AB ou BA, se apresentaram mais desenvolvidos nos perfis de solos que receberam tratamento, verificando-se que naquele tratado durante 17 anos, o volume $\mathrm{A}(\mathrm{Ap}+\mathrm{AB}$ ou BA) se encontrou mais profundo. Isto devido, possivelmente, a uma ampla mobilidade dos componentes da matéria orgânica humificada, quê tingem de marrom escuro parte dos horizontes óxidos (Bo), ou seja, processo de melanização, (Malagón 1976 , Garavito 1979, Kiehl 1985) (Tab. 1).

A quantidade de argila varia de um horizonte para outro, sem caracterizar um horizonte textural, sendo isto típico para latossolo (Vieira \& Vieira 1983). Estas modificações, entretanto, refletem-se no comportamento da densidade aparente, que apresentaram valores mais elevados, possivelmente devido a presença de matéria orgânica Mull Florestal, que não causa agregação, mas sim adensamento (Tab. 2). Tal fato contribui para reduzir as características, tais como: porosidade total e infiltração (Garavito 1979, Kiehl 1985). A atividade e o tipo de argilas de acordo com Goosen (1971), podem ser classificados 
Tabela 1-Características morfológicas dos perfis (AJ 1 -AJ5)

Table 1 - Morphological characteristics of the profiles (AJ 1 - AJ 5)

\begin{tabular}{|c|c|c|c|c|c|c|}
\hline Horizontes & Profundidude & $\operatorname{Cor}^{2 /}$ & Texturat & Estrutura & Consiststencia" & Transiçio \\
\hline \multicolumn{7}{|c|}{$\mathrm{AJ}_{1}$} \\
\hline $\begin{array}{l}\mathbf{A p} \\
\mathbf{A B} \\
\mathbf{B 1} \\
\mathbf{B 2}\end{array}$ & $\begin{array}{r}0=23 \\
23=51 \\
51=71 \\
71=92\end{array}$ & $\begin{array}{l}7.5 Y R 4 / 2 \\
7.5 Y R \quad 4 / 2-4 \\
5 Y R 4 / 4 \\
5 Y R \quad 5 / 4\end{array}$ & $\begin{array}{l}\text { Barro arenoso } \\
\text { Barro argarenoso } \\
\text { Barro argarenoso } \\
\text { Barro arg-arenoso }\end{array}$ & $\begin{array}{l}\text { for, med-grd,megr } \\
\text { mod, med-grd, me BS } \\
\text { mod-for, med-gd, BS } \\
\text { fr-mod, med-peq, BS }\end{array}$ & $\begin{array}{l}\text { fir-fri, mpl, npg } \\
\text { fii-fir, npl,Jpg } \\
\text { fii-fir, npl.Jpg } \\
\text { fin, npl, lpg }\end{array}$ & $\begin{array}{l}\text { gradual,ondulado } \\
\text { difuso,iregular } \\
\text { difuso,iregular } \\
\text { difuso,imegular }\end{array}$ \\
\hline \multicolumn{7}{|c|}{$\mathrm{AJ} 2$} \\
\hline $\begin{array}{l}\mathrm{Ap} \\
\mathrm{BO} 1 \\
\mathrm{BO} 2 \\
\mathrm{BO} 3\end{array}$ & $\begin{array}{r}0-20 \\
20 \cdot 43 \\
43=78 \\
78=150\end{array}$ & $\begin{array}{l}\text { SYR } 4 / 2 \\
\text { SYR } 3,5 / 4 \\
\text { SYR 4,5/4 } \\
\text { SYR } 4 / 4\end{array}$ & $\begin{array}{l}\text { Bamo arg-arenoso } \\
\text { Barro arg-arenoso } \\
\text { Barro arg-birenoso } \\
\text { Barno arg-urenoso }\end{array}$ & $\begin{array}{l}\text { mod-for, med-gid, mçs } \\
\text { mod, med-gri, mic BS } \\
\text { mod-fi, med-peq., BS } \\
\text { t, med-peq, BS }\end{array}$ & $\begin{array}{l}\text { fir-fir, opl.Jpg } \\
\text { firt, npl, lpg } \\
\text { fir-mfin, npt, lpg } \\
\text { mfr,npl,Jpg }\end{array}$ & $\begin{array}{l}\text { gradual,ondnlado } \\
\text { difuso,inegular } \\
\text { difuso,imegular }\end{array}$ \\
\hline \multicolumn{7}{|c|}{ Av3 } \\
\hline $\begin{array}{l}\mathrm{AP} \\
\mathrm{AB} \\
\mathrm{BO} 1 \\
\mathrm{BO} 2\end{array}$ & $\begin{array}{r}0=16 \\
16=42 \\
42=78 \\
78=150\end{array}$ & $\begin{array}{l}5 Y R 4 / 2 \\
5 Y R 4 / 2 \\
5 Y R ~ 3,5 / 4 \\
5 Y R ~ 4 / 4\end{array}$ & $\begin{array}{l}\text { Barro artenoso } \\
\text { Barro arg-artroso } \\
\text { Barro argarenoso } \\
\text { Barro arg.arenoso }\end{array}$ & $\begin{array}{l}\text { mod, med-grd, megr } \\
\text { mod-fi, med-grd,BS } \\
\text { mod-fr, med, BS } \\
\text { f, med-peq, BS }\end{array}$ & $\begin{array}{l}\text { fir, npl, lpg } \\
\text { fri, npl,plg } \\
\text { fri, npl, plg } \\
\text { mfri, npl, lpg }\end{array}$ & $\begin{array}{l}\text { gradural, onduado } \\
\text { gradual,ondulado } \\
\text { difuso, irregular }\end{array}$ \\
\hline \multicolumn{7}{|c|}{ AJ4 } \\
\hline $\begin{array}{l}\mathrm{AP} \\
\mathrm{AB} \\
\mathrm{BA} \\
\mathrm{BO} 1 \\
\mathrm{BO} 2\end{array}$ & $\begin{array}{r}0-14 \\
14=32 \\
32=57 \\
57=71 \\
71=150\end{array}$ & $\begin{array}{l}\text { SYR 4/2 } \\
\text { SYR 4/2 } \\
\text { SYR 4/2 } \\
\text { SYR 4/6 } \\
\text { SYR 4/6 }\end{array}$ & $\begin{array}{l}\text { Barro arg.arenoso } \\
\text { Barro arg-arenoso } \\
\text { Barro arg. arenoso } \\
\text { Barro arg.arenoso } \\
\text { Barno arg-arenoso }\end{array}$ & $\begin{array}{l}\text { mod-for, med-grd, gr } \\
\text { mod, peq-med, mc BS } \\
\text { mod, med, BS } \\
\text { fr, med-grd, BS } \\
\text { fi-mf, med-peq, BS }\end{array}$ & $\begin{array}{l}\text { fri-fir, npl, lpg } \\
\text { fin-fir, npl, lpg } \\
\text { fri, npl, lpg } \\
\text { fri, mfri, npl, lpg }\end{array}$ & $\begin{array}{l}\text { gradual,ondulado } \\
\text { gradual,ondulado } \\
\text { difuso, irregular } \\
\text { difuso,irregular }\end{array}$ \\
\hline \multicolumn{7}{|c|}{ AJ5 } \\
\hline $\begin{array}{l}\mathrm{Ap} \\
\mathrm{BA} \\
\mathrm{BO} 1 \\
\mathrm{BO} 2 \\
\mathrm{BO} 3\end{array}$ & $\begin{array}{r}0-20 \\
20-46 \\
46-68 \\
68-107 \\
107-150\end{array}$ & $\begin{array}{l}7,5 Y R 4 / 2 \\
5 Y R 4 / 4 \\
\text { SYR } 5 / 5 \\
5 Y R \text { 5/6 } \\
\text { SYR } 5 / 6\end{array}$ & $\begin{array}{l}\text { Barro arenoso } \\
\text { Barro arenoso } \\
\text { Barro arg.arenoso } \\
\text { Barro arg- arenoso } \\
\text { Barro arg.arenoso }\end{array}$ & $\begin{array}{l}\text { mod, peq-grd, megr } \\
\text { mod, peq-med, mkgr } \\
\text { mfr, med-grd, BS } \\
\text { mfi, med-peq, BS } \\
\text { fi, med-grd, BS }\end{array}$ & $\begin{array}{l}\text { fri, npl, npg } \\
\text { fri, npl, npg } \\
\text { fri-mfri, npl, lpg } \\
\text { mfri, npl, lpg } \\
\text { mfri, npl, lpg }\end{array}$ & $\begin{array}{l}\text { claro,ondulado } \\
\text { gradaat, ondulado } \\
\text { difuso,ondulado } \\
\text { difuso, ondulado }\end{array}$ \\
\hline
\end{tabular}

1) Cor do solo úmido, segundo Munsell soil color charts

2) Textura: classe textural segundo USA (1951)

3) Estrutura: $\mathrm{mfr}=$ muito $\mathrm{fraca} ; \mathrm{fr}=\mathrm{fraca}$; $\bmod =$ moderada; for $=$ forte; peq = pequena; med = média; grd = grande; $g r=$ granular, $\mathrm{BS}=\mathrm{blocos}$ subangulares; me $=$ maciça que se desfaz

4) Consistência: fri = friável; $\mathrm{mfri}$ = muito friável; fir=firme; $\mathrm{npl}=$ não plástico; $\mathrm{npg}$ = não pegajoso; Ipg = ligeiramente pegajoso.

como argilas caulinítícas de atividade média em todos os perfis, em especial nas maiores profundidades e, em alguns casos, baixa atividade na superfície, como nos tratamentos zero e seis anos (Tab. 2).

A estrutura original apresentou desenvolvimento muito fraco a moderado, chegando a ser maciça. De acordo com Wambeke (1974), entretanto, os solos originalmente sob vegetação de cerrado apresentam $70 \%$ de agregados, aspecto este divergente em relação ao solo testemunho, que apresentou valores que variaram entre 4 e $27 \%$ de agregados em meio aquoso e entre 34 e $60 \%$ no meio seco. Assim, este mostrou-se extremadamente agregado na superfície, devido a ser maciço que se desfaz em granular grande. A adição de estéreo de frango no solo não variou este aspecto, pois estas porcentagens continuaram dominantes, demonstrando que a matéria orgânica aplicada apresentou-se na forma de húmus do tipo Mull Florestal ácido (Tab. 6). Este último possui alto teor de ácidos fulvicos, que apresentam-se com ampla mobilidade e desestabilizam a estrutura do solo (Garavito 1979). As porcentagens de agregados, que permitiram a apreciação da degradação da estrutura após a plantação de amoreira, entre 0,2 e 52\%, forneceram características de muito mal na superfície a bom em maior profundidade, e bom em todos os volumes de altera- ção nos solos tratados até 2,5 e 6 anos em seco. Nos demais tratamentos, até mesmo o testemunho, apresentaram um comportamento mal a muito mal na superfície e bom a muito bom em maiores profundidades, relacionando-se com o tipo de húmus e com os efeitos da cultura sobre a estruturação do solo, decorrente de seu poder desagregador, por possuir um sistema radicular pivotante (Malagón 1976 e Souza et al. 1982). O algodão promoveu uma degradação acentuada da estrutura, efeito este semelhante ao da amoreira; o mesmo resultado foi encontrado por Cintra \& Mielniczuk (1983), onde a amoreira não penetrou totalmente no solo, como no caso de tremoso, em que o nível de compactação foi de $11 \mathrm{~kg} \mathrm{~cm}^{\prime 2}$, diferente do que ocorreu no presente estudo (Tab. 7). Nesta, observa-se que os resultados dos agregados maiores de $2 \mathrm{~mm}$ são dominantes, variando de 62 a $97 \%$, o que está em acordo com os efeitos produzidos pelo tipo de matéria orgânica em que dominam os ácidos fulvicos, os que promovem o adensamento e portanto a perda da agregação total do solo. Entretanto, Angulo et al. (1984) e Nuernberg et al. (1986) demonstram que os agregados $>1$ ou $>2 \mathrm{~mm}$ podem ser utilizados na caracterização do estado estrutural do solo como de boa qualidade para o desenvolvimento das culturas, permeabilidade, troca de ar e de cations. 
Tabela 2 - Características fisicas dos perfis (AJ1 - AJ5)

Table 2 - Physical characteristics of the profiles (AJ1 - AJS)

\begin{tabular}{|c|c|c|c|c|c|c|c|c|c|c|c|c|c|c|}
\hline \multirow{2}{*}{$\begin{array}{l}\text { Hori- } \\
\text { not- } \\
0 \\
0\end{array}$} & \multirow{2}{*}{$\begin{array}{l}\text { Umids } \\
\text { derela- } \\
\text { tiva } \\
\%\end{array}$} & \multirow{2}{*}{$\begin{array}{c}\text { Porosi- } \\
\text { dode } \\
\text { cotal } \\
\text { gmkeme }\end{array}$} & \multirow{2}{*}{$\begin{array}{c}\text { Dentsi } \\
\text { deded } \\
\text { reat } \\
\text { gentem? }\end{array}$} & \multirow{2}{*}{$\begin{array}{l}\text { Densi- } \\
\text { dade } \\
\text { sparente } \\
\text { gon/cont }\end{array}$} & \multicolumn{7}{|c|}{ Granulometria } & \multicolumn{2}{|c|}{ Limites } & \multirow{2}{*}{ Textura } \\
\hline & & & & & $\begin{array}{l}\text { Arcia } \\
\text { muito } \\
\text { grossa } \\
\%\end{array}$ & $\begin{array}{c}\text { Areis } \\
\text { gross: } \\
\%\end{array}$ & $\begin{array}{c}\text { Arein } \\
\text { modia } \\
\%\end{array}$ & $\begin{array}{c}\text { Areia } \\
\text { fins } \\
\text { \% }\end{array}$ & $\begin{array}{c}\text { Arcis } \\
\text { muito } \\
\text { fing } \\
\%\end{array}$ & $\begin{array}{c}\text { Sile } \\
\%\end{array}$ & $\begin{array}{c}\text { Argila } \\
\%\end{array}$ & 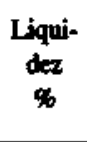 & $\begin{array}{l}\text { Plastici- } \\
\text { dade }\end{array}$ & \\
\hline \multicolumn{15}{|c|}{ AJ 1} \\
\hline $\begin{array}{l}\mathrm{AP} \\
\mathrm{AB} \\
\mathrm{BO} \\
\mathrm{BO} 2 \\
\mathrm{BO} 3\end{array}$ & $\begin{array}{l}10,25 \\
10,45 \\
12,33 \\
16,62 \\
16,65\end{array}$ & $\begin{array}{l}37 \\
40 \mathrm{NS} \\
43 \mathrm{MB} \\
47 \mathrm{NS} \\
44 \mathrm{NS}\end{array}$ & $\begin{array}{l}2,62 \\
2,67 \\
2,64 \\
2,67 \\
2,68\end{array}$ & $\begin{array}{l}1,65 \\
1,58 \\
1,49 \\
1,40 \\
1,48\end{array}$ & $\begin{array}{l}0,72 \\
0,43 \\
0,51 \\
0,58 \\
0,42\end{array}$ & $\begin{array}{l}2,82 \\
2,57 \\
2,51 \\
2,60 \\
2,70\end{array}$ & $\begin{array}{l}23,43 \\
24,79 \\
21,54 \\
23,12 \\
24,56\end{array}$ & $\begin{array}{l}39,44 \\
30,27 \\
39,95 \\
31,01 \\
30,81\end{array}$ & $\begin{array}{l}14,18 \\
18,37 \\
16,33 \\
18,05 \\
17,54\end{array}$ & $\begin{array}{l}3,44 \\
2,84 \\
1,15 \\
2,89 \\
2,94\end{array}$ & $\begin{array}{l}15,94 \\
21,25 \\
21,20 \\
22,53 \\
21,01\end{array}$ & $\begin{array}{l}22,3 \\
20,8 \\
17,2 \\
16,7 \\
21,5\end{array}$ & $\begin{array}{l}\mathrm{np} \\
\mathrm{pp} \\
\mathrm{np} \\
\mathrm{np}\end{array}$ & $\begin{array}{l}\text { Barro arenoso } \\
\text { Baro argilo-arenoso } \\
\text { Barro argilo-ancnoso } \\
\text { Bamo argilo-anenoso } \\
\text { Barro argilo-anenoso }\end{array}$ \\
\hline \multicolumn{15}{|c|}{ A 2} \\
\hline $\begin{array}{l}\text { AP } \\
\text { BO1 } \\
\text { BO2 } \\
\text { BO3 }\end{array}$ & $\begin{array}{l}13,88 \\
13,78 \\
16,55 \\
14,35\end{array}$ & $\begin{array}{l}40 \mathrm{MB} \\
41 \mathrm{NS} \\
47 \mathrm{NS} \\
49 \mathrm{NS}\end{array}$ & $\begin{array}{l}2,67 \\
2,62 \\
2,67 \\
2,63\end{array}$ & $\begin{array}{l}1,60 \\
1,53 \\
1,40 \\
1,34\end{array}$ & $\begin{array}{l}0,43 \\
0,21 \\
0,29 \\
0,23\end{array}$ & $\begin{array}{l}2,35 \\
2,1 \\
2,31 \\
1,93\end{array}$ & $\begin{array}{l}22,71 \\
21,60 \\
25,93 \\
20,47\end{array}$ & $\begin{array}{l}39,06 \\
35,76 \\
28,31 \\
39,5\end{array}$ & $\begin{array}{l}12,17 \\
13,17 \\
15,31 \\
13,97\end{array}$ & $\begin{array}{l}1,75 \\
3,55 \\
2,88 \\
1,78\end{array}$ & $\begin{array}{l}20,95 \\
23,55 \\
24,60 \\
26,03\end{array}$ & $\begin{array}{l}22,1 \\
19,1 \\
18,7 \\
16,3\end{array}$ & $\begin{array}{l}\text { qp } \\
\text { qp } \\
\text { qp }\end{array}$ & $\begin{array}{l}\text { Bamo argilo-arenoso } \\
\text { Barro argilo-amoso } \\
\text { Bano angilo-arenoso } \\
\text { Bamo angilo-arenoso }\end{array}$ \\
\hline
\end{tabular}

\begin{tabular}{|c|c|c|c|c|c|c|c|c|c|c|c|c|c|c|}
\hline \multicolumn{15}{|c|}{ A 3} \\
\hline $\mathbf{A P}$ & 9,39 & $44 \mathrm{NS}$ & 2,65 & 1,48 & 0,6 & 2,39 & 21,70 & 40,72 & 13,66 & 6,89 & 14,03 & 23,8 & 14 & Barro arenoso \\
\hline $\mathbf{A B}$ & 8,97 & $45 \mathrm{NS}$ & 2,69 & 1,49 & 0,07 & 1,86 & 2,41 & 30,51 & 16,11 & 4,78 & 24,17 & 22,9 & $\mathbf{n p}$ & Barro argilo-arenoso \\
\hline BOI & 9,05 & $46 \mathrm{NS}$ & 2,68 & 1,45 & 0,08 & 2,15 & 23,68 & 29,10 & 15,92 & 4,56 & 24,43 & 20,6 & $\mathbf{q p}$ & Barroangilo-arenoso \\
\hline $\mathrm{BO} 2$ & 9,03 & $43 \mathrm{NS}$ & 2,65 & 1,42 & 0,15 & 1,55 & 18,11 & 35,70 & 16,10 & 3,72 & 24,65 & 17,83 & p & Barro argilo-arenoso \\
\hline
\end{tabular}

\begin{tabular}{|c|c|c|c|c|c|c|c|c|c|c|c|c|c|c|}
\hline \multicolumn{15}{|c|}{$\mathrm{A}^{4}$} \\
\hline AP & 9,53 & $44 \mathrm{NS}$ & 2,69 & 1,48 & 1,15 & 5,86 & 23,97 & 36,27 & 11,42 & 1,86 & 20,45 & 24,0 & 听 & Barro argilo-arenoso \\
\hline AB & 9,06 & $42 \mathrm{NS}$ & 2,66 & 1,53 & 0,7 & 3,88 & 24,46 & 31,67 & 14,22 & 2,54 & 22,50 & 22,0 & np & Barro argito-arenoso \\
\hline $\mathbf{B A}$ & 9,01 & $43 \mathrm{NS}$ & 2,62 & 1,47 & 0,56 & 4,19 & 26,84 & 24,29 & 15,33 & 2,73 & 26,03 & 18,61 & np & Barro argilo-arenoso \\
\hline BO1 & 8,99 & $45 \mathrm{NS}$ & 2,68 & 1,45 & 0,44 & 3,54 & 26,43 & 25,97 & 16,97 & 2,06 & 24,56 & 20,77 & ip & Barro argilo-arencoso \\
\hline $\mathrm{BO} 2$ & 9,08 & $45,5 \mathrm{NS}$ & 2,65 & 1,44 & 0,56 & 4,31 & 28,52 & 23,39 & 14,95 & 2,57 & 25,65 & 22,09 & m & Barro argilo-antnoso \\
\hline
\end{tabular}

\begin{tabular}{|c|c|c|c|c|c|c|c|c|c|c|c|c|c|c|}
\hline \multicolumn{15}{|c|}{ A 5} \\
\hline AP & 13,10 & $38 \mathrm{MB}$ & 2,64 & 1,62 & 1,81 & 7,06 & 36,55 & 19,39 & 15,68 & 6,56 & 12,91 & 19,5 & $\mathbf{p}$ & Barto arenoso \\
\hline $\mathbf{B A}$ & 10,72 & $44 \mathrm{NS}$ & 2,69 & 1,51 & 1,29 & 6,62 & 37,24 & 17,32 & 16,52 & 4,00 & 16,98 & 21,0 & $\mathbf{p p}$ & Barro arentaso \\
\hline BO1 & 10,71 & $47 \mathrm{NS}$ & 2,67 & 1,41 & 1,62 & 5,54 & 33,94 & 17,31 & 18,09 & 1,79 & 21,72 & 23.5 & 4 & Bemo argilo-arenoso \\
\hline $\mathrm{BO} 2$ & 10,05 & $50 \mathrm{NS}$ & 2,69 & 1,35 & 1,19 & 4,08 & 33,31 & 17,81 & 18,50 & 4,07 & 21,00 & 25,07 & np & Barro argilo-arentoso \\
\hline $\mathrm{BO3}$ & 14,04 & $48 \mathrm{NS}$ & 2,63 & 1,37 & 1,00 & 5,76 & 31,09 & 17,89 & 18,03 & 4,25 & 21,95 & 26,2 & $\mathbf{n}$ & Bamoargilo-arenoso \\
\hline
\end{tabular}

NS =Nöo-Satisfatcria para a comada erfvel

MB = Muito Baixa, topica de horizontes ilaviais compactados. Segundo Katrichev (1984)

O grau de agregação não chega sequer a $30 \%$, indicando com isto um efeito muito baixo da matéria orgânica aplicada em favor da estruturação, contrariando o comentado por Kiehl (1985) e confirmando que no tipo de Mull ácido a mineralização da matéria orgânica é muito ativa, conduzindo à cimentação e destruição de agregados, evidenciado pela quantidade dos agregados $>2 \mathrm{~mm}$ (Tab. 7).

Os índices de apreciação da degradação estrutural mostram que os tratamentos mais adequados e comparáveis ao solo testemunho foram aqueles com aplicações durante 2,5/6 e 13 anos, onde a degradação foi de baixa a muito baixa. O tratamento de 17 anos foi o mais afetado, chegando de 25 a $70 \%$ a degradação em imersão, de acordo com Malagón (1976) (Tab. 3).

$\mathrm{O}$ índice $\mathrm{K}$ em meio aquoso demonstra, de acordo com seus valores, que em geral a estrutura está caracterizada como de muito mal a mal desenvolvida, o que está em acordo com a apreciação do estado estrutural do solo segundo Kaúrichev (1984), que apresenta valores inferiores a 30\% indicando com isto, que o estado de estruturação em imersão é muito mal.

Os diâmetros médios geométricos em imersão se apresentaram com valores médios maiores de $0,6 \mathrm{~mm}$ (Tab. 3) que, de acordo com Malagón (1976), este tamanho de agregado é o melhor no manejo da estrutura para o desenvolvimento adequado das culturas.

Com relação ao processo em seco, pode-se dizer que a desestabilização da estrutura foi alta a muito alta, variando entre porcentagens de agregados $<500$ de 0 a $90 \%$. O estado estrutural do solo varia de muito mal a muito bom ou bom nos diversos tratamentos, sendo que os melhores tratamentos são de dois anos e meio a seis anos de aplicação da matéria orgânica no meio seco. Entretanto, Gomes et al. (1978) encon- 
Tabela 3 - Caracterização da estabilidade estrutural em meio aquoso sob pressão atmosférica de um latossolo vermelho-amarelo Table 3 - Structural stability characterization on aquous environment under atmospheric pressure of a red-yellowshield latossol

\begin{tabular}{|c|c|c|c|c|c|c|c|c|c|c|c|c|}
\hline \multirow{3}{*}{$\begin{array}{l}\text { Pefil } \\
\text { A } 1\end{array}$} & \multirow{3}{*}{$\begin{array}{l}\text { Hori- } \\
\text { zome } \\
<5 \\
\text { Ap } \\
\text { AB } \\
\text { BO1 } \\
\text { BO2 } \\
\text { BO3 }\end{array}$} & \multirow{3}{*}{$\begin{array}{l}\text { Manejo } \\
\text { em anos } \\
17\end{array}$} & $<250$ & $250-500$ & $500-1000$ & $1000-2000$ & $>2000$ & \multirow{3}{*}{\begin{tabular}{|c}
$\begin{array}{c}\text { Dilametro } \\
\text { motio } \\
\text { geomt } \\
\text { tico } \\
\text { (mim) }\end{array}$ \\
0,634 \\
0,689 \\
0,520 \\
0,610 \\
0,439
\end{tabular}} & \multirow{3}{*}{\begin{tabular}{|r|} 
fodice \\
\\
23 \\
7 \\
30 \\
17 \\
16 \\
\end{tabular}} & \multirow{3}{*}{$\begin{array}{l}\text { Apreciacio do } \\
\text { estado estru- } \\
\text { tural do solo } \\
\text { muito mal } \\
\text { muito mal } \\
\text { mal } \\
\text { muito mal } \\
\text { muito mal }\end{array}$} & \multirow{3}{*}{\begin{tabular}{|c}
$\begin{array}{c}\text { Apreciacflo da } \\
\text { gratuaçlo } \\
\text { estrutural } \\
\%\end{array}$ \\
Mediana \\
Mediana \\
Mediana \\
Mediana \\
Muilo alta
\end{tabular}} & \multirow{3}{*}{$\begin{array}{c}\text { Grau } \\
\text { de } \\
\text { age } \\
\text { gucto }\end{array}$} \\
\hline & & & \multicolumn{5}{|c|}{ To de agregadoe em } & & & & & \\
\hline & & & $\begin{array}{l}19,00 \\
22,01 \\
23,56 \\
22,76 \\
38,67\end{array}$ & $\begin{array}{l}6,42 \\
3,35 \\
9,90 \\
5,17 \\
7,35\end{array}$ & $\begin{array}{l}7,95 \\
2,30 \\
6,86 \\
5,45 \\
3,52\end{array}$ & $\begin{array}{l}4,50 \\
0,89 \\
6,44 \\
3,64 \\
2,70\end{array}$ & $\begin{array}{l}62,13 \\
71,45 \\
53,24 \\
62,98 \\
47,76\end{array}$ & & & & & \\
\hline AJ2 & $\begin{array}{l}\mathrm{Ap} \\
\mathrm{BO} 1 \\
\mathrm{BO} 2 \\
\mathrm{BO3}\end{array}$ & 13 & $\begin{array}{r}3,05 \\
19,93 \\
11,97 \\
26,50\end{array}$ & $\begin{array}{r}0,18 \\
7,51 \\
6,77 \\
13,50\end{array}$ & $\begin{array}{r}0,03 \\
7,03 \\
9,08 \\
16,00\end{array}$ & $\begin{array}{r}0,00 \\
0,02 \\
11,43 \\
17,00\end{array}$ & $\begin{array}{l}96,74 \\
69,51 \\
60,75 \\
27,00\end{array}$ & $\begin{array}{l}1,294 \\
0,705 \\
0,718 \\
0,872\end{array}$ & $\begin{array}{l}0,2 \\
17 \\
37 \\
16\end{array}$ & $\begin{array}{l}\text { mutito mal } \\
\text { muito mal } \\
\text { mal } \\
\text { Boin }\end{array}$ & $\begin{array}{l}\text { Muito baixa } \\
\text { Mediana } \\
\text { Alta } \\
\text { Alta }\end{array}$ & $\begin{array}{l}23 \\
31 \\
27 \\
41\end{array}$ \\
\hline A 3 & $\begin{array}{l}\mathrm{Ap} \\
\mathrm{AB} \\
\mathrm{BO} \\
\mathrm{BO} 2\end{array}$ & 6 & $\begin{array}{l}11,70 \\
27,98 \\
21,95 \\
18,66\end{array}$ & $\begin{array}{l}1,36 \\
6,43 \\
4,87 \\
5,71\end{array}$ & $\begin{array}{r}1,33 \\
4,14 \\
12,27 \\
8,56\end{array}$ & $\begin{array}{r}0,02 \\
0,47 \\
12,15 \\
5,87\end{array}$ & $\begin{array}{l}85,59 \\
61,08 \\
48,76 \\
61,20\end{array}$ & $\begin{array}{l}0,975 \\
0,537 \\
0,539 \\
0,638\end{array}$ & $\begin{array}{r}3 \\
12 \\
41 \\
25\end{array}$ & $\begin{array}{l}\text { muito mill } \\
\text { muito mall } \\
\text { mal } \\
\text { mal }\end{array}$ & $\begin{array}{l}\text { Baixa } \\
\text { Mediana } \\
\text { Mediana } \\
\text { Mediana }\end{array}$ & $\begin{array}{l}21 \\
29 \\
29 \\
28\end{array}$ \\
\hline A 4 & $\begin{array}{l}\mathbf{A p} \\
\mathbf{A B} \\
\mathbf{B A} \\
\mathbf{B O 1} \\
\mathbf{B O 2}\end{array}$ & 2,5 & $\begin{array}{r}10,12 \\
16,27 \\
7,09 \\
17,83 \\
27,53\end{array}$ & $\begin{array}{r}0,72 \\
5,51 \\
1,33 \\
7,59 \\
13,08\end{array}$ & $\begin{array}{r}0,15 \\
3,70 \\
3,50 \\
19,07 \\
5,62\end{array}$ & $\begin{array}{r}0,23 \\
3,19 \\
5,93 \\
6,14 \\
33,51\end{array}$ & $\begin{array}{c}88,7 \\
71,33 \\
82,15 \\
49,37 \\
20,25\end{array}$ & $\begin{array}{l}1,048 \\
0,746 \\
1,033 \\
0,541 \\
0,368\end{array}$ & $\begin{array}{l}1 \\
14 \\
12 \\
49 \\
1.09\end{array}$ & $\begin{array}{l}\text { muito mal } \\
\text { muito mal } \\
\text { muito mal } \\
\text { mal } \\
\text { Bom }\end{array}$ & $\begin{array}{l}\text { Baixa } \\
\text { Mediana } \\
\text { Muito baixa } \\
\text { Mediana } \\
\text { Alia }\end{array}$ & $\begin{array}{l}21 \\
25 \\
29 \\
27 \\
29\end{array}$ \\
\hline A 5 & $\begin{array}{l}\mathrm{AP} \\
\mathrm{BA} \\
\mathrm{BO} 1 \\
\mathrm{BO2} \\
\mathrm{BO} 3\end{array}$ & 0 & $\begin{array}{l}10,06 \\
12,63 \\
36,59 \\
22,89 \\
37,91\end{array}$ & $\begin{array}{r}3,10 \\
3,12 \\
4,85 \\
8,23 \\
10,78\end{array}$ & $\begin{array}{r}0,73 \\
3,59 \\
5,49 \\
12,30 \\
2,65\end{array}$ & $\begin{array}{r}0,32 \\
0,61 \\
0,50 \\
4,97 \\
13,42\end{array}$ & $\begin{array}{l}85,88 \\
80,05 \\
52,57 \\
51,61 \\
35,24\end{array}$ & $\begin{array}{l}0,992 \\
0,884 \\
0,428 \\
0,514 \\
0,346\end{array}$ & $\begin{array}{r}4 \\
8 \\
12 \\
34 \\
37\end{array}$ & $\begin{array}{l}\text { muito mal } \\
\text { muito mal } \\
\text { muito mal } \\
\text { mal } \\
\text { lnal }\end{array}$ & $\begin{array}{l}\text { Baixa } \\
\text { Baixa } \\
\text { Alta } \\
\text { Median } \\
\text { Alta }\end{array}$ & $\begin{array}{l}20 \\
21 \\
24 \\
25 \\
26\end{array}$ \\
\hline
\end{tabular}

tram que existe uma degradação da estruturação do solo testemunho com relação ao efeito dos sistemas e tempo de cultivos num podzólico vermelho-amarelo. Neste presente estudo, pode-se observar um decréscimo de mais de $50 \%$ dos agregados estáveis em superfície e um incremento de 10 a $20 \%$ em profundidade em estado úmido. $\mathrm{O}$ índice $\mathrm{K}$ apresenta valores muito variáveis. Entretanto em superfície, o índice de desenvolvimento da estrutura é muito baixo, e em profundidade é muito bom no tratamento de dois anos e meio; já no tratamento de treze anos é a superfície que se mostra melhor desenvolvida de acordo a classificação de Kaúrichev (1984) (Tab. 4).

Os diâmetros médios geométricos em seco são em geral $<0,577 \mathrm{~mm}$, o que os torna, segundo Malagón (1976), mais susceptíveis à erosão eólica (Tab. 4).

Os melhores tratamentos foram os de dois anos e meio, seis e treze anos de aplicação de estéreo de frango, em relação ao desenvolvimento integral da estrutura e sua estabilidade em condições úmidas. Para as épocas secas deve ter-se cuidado com o solo devido a sua fragilidade, fazendo-se necessária a presença de vegetal, para assim evitar a erosão e desagregação da estrutura por efeito eólico. Além disso propõe-se a utilização de uma mistura de serragem ao estrume de frango, para incrementar sua capacidade de agregação de partículas primárias do solo. Segundo Kiehl (1985) quantidade e tipo de matéria orgânica. Com o desenvolvimento e estabilidade da estrutura, pode-se dizer que o solo estudado apresentou uma relação ácido fúlvico/ácido húmico, maior do que 1,0 (Tab. 6), demonstrando uma dominância dos ácidos fulvicos, promovendo assim uma maior mobilidade de alguns colóides mine- rais, como os oxi-hidróxidos de ferro e alumínio, a mais das argilas (Jimenez et al. 1976, Garavito 1979). Este efeito repercute em um baixo grau de agregação das partículas, uma degradação estrutural de muito baixa a mediana, em úmido, estado estrutural de muito mal a mal e índice de estruturação muito baixo (Tabs. 3 e 4 ).

Por sua vez, os diversos tempos de aplicação determinaram que a fertilidade atual se incrementa consideravelmente, já que o $\mathrm{pH}$ se modifica passando de valores ácidos 5, para ligeiramente ácidos, 6, e neutro, 7, sendo que, os tempos de adição de estrume de frango que se mostraram mais adequados, foram os de 6,13 e 17 anos. Quanto às cargas negativas para a troca catiônica, observou-se que estas aumentaram através do tempo de aplicação; o mesmo foi observado com relação a soma das bases e sua saturação total.

Tudo isto devido a que os incrementos em cálcio, magnésio, potássio e fósforo muito altos, manifestam uma melhoria nas características químicas dos elementos trocáveis, que favorecem o desenvolvimento das plantas (Tab. 5) (Jorge 1983, Kiehl 1985, Primavesi 1980, Mello et al 1983 e Garavito 1979).

Os conteúdos de matéria orgânica foram incrementados em $21 \%$ quando comparados ao solo-testemunho, e com isto, além dos benefícios em relação com a fertilidade atual, normalização na seção dos elementos, regularizam a temperatura do solo, favorecendo um melhor e maior desenvolvimento e atividade dos microorganismos do mesmo.

Estatisticamente, os microorganismos não apresentaram números diferentes em relação aos tratamentos estudados. Contudo, houve uma tendência de ocorrer aumento do número de bactérias, em relação ao testemunho 52 para 43 x 108 no solo 
Tabela 4 - Caracterização da estabilidade estrutural em seco

Table 4 - Structural stability characterization on dry

\begin{tabular}{|c|c|c|c|c|c|c|c|c|c|c|c|c|}
\hline \multirow{2}{*}{ Pefil } & \multirow{2}{*}{$\begin{array}{l}\text { Hori- } \\
\text { zoove }\end{array}$} & \multirow{2}{*}{$\begin{array}{l}\text { Mangjo } \\
\text { em anos }\end{array}$} & $<250$ & $250-500$ & $500-1000$ & $1000-2000$ & $>2000$ & \multirow{2}{*}{$\begin{array}{c}\text { Média } \\
\text { Geons } \\
\text { trica } \\
\text { (mm) }\end{array}$} & \multirow{2}{*}{$\begin{array}{l}\text { Indice } \\
\mathbf{K}\end{array}$} & \multirow{2}{*}{$\begin{array}{l}\text { Apreciactio do } \\
\text { estado estru- } \\
\text { ural do solo }\end{array}$} & \multirow{2}{*}{$\begin{array}{l}\text { Apreciaplo da } \\
\text { degradactio } \\
\text { estrutteral }\end{array}$} & \multirow{2}{*}{$\begin{array}{c}\text { Grau } \\
\text { de } \\
\text { agre } \\
\text { gapox }\end{array}$} \\
\hline & & & \multicolumn{5}{|c|}{ \% de agregados em } & & & & & \\
\hline$\overline{\mathrm{A} J 1}$ & $\begin{array}{l}\text { Ap } \\
\mathbf{A B} \\
\text { BO1 } \\
\text { BO2 } \\
\text { BO3 }\end{array}$ & 17 & $\begin{array}{l}19,12 \\
33,65 \\
42,14 \\
46,89 \\
52,83\end{array}$ & $\begin{array}{l}14,66 \\
40,67 \\
41,13 \\
40,47 \\
41,18\end{array}$ & $\begin{array}{l}3,54 \\
8,70 \\
7,58 \\
6,05 \\
5,25\end{array}$ & $\begin{array}{l}1,60 \\
4,08 \\
3,07 \\
4,38 \\
0,74\end{array}$ & $\begin{array}{r}61,08 \\
12,90 \\
5,28 \\
2,21 \\
0,00\end{array}$ & $\begin{array}{l}0,577 \\
0,206 \\
0,161 \\
0,148 \\
0,128\end{array}$ & $\begin{array}{c}25 \\
1,5 \\
1,09 \\
1,04 \\
89\end{array}$ & $\begin{array}{l}\text { mutito mal } \\
\text { bom } \\
\text { bom } \\
\text { bom } \\
\text { bom }\end{array}$ & $\begin{array}{l}\text { Mediana } \\
\text { Muito ata } \\
\text { Muito alta } \\
\text { Muito alta } \\
\text { Muito alta }\end{array}$ & $\begin{array}{l}19 \\
24 \\
22 \\
25 \\
24\end{array}$ \\
\hline$\overline{\mathbf{A} 2}$ & $\begin{array}{l}\mathrm{Ap} \\
\mathrm{BO} 1 \\
\mathrm{BO} 2 \\
\mathrm{BO} 3\end{array}$ & 13 & $\begin{array}{r}25,11 \\
37,42 \\
40,25 \\
0,00\end{array}$ & $\begin{array}{r}25,82 \\
35,30 \\
40,34 \\
0,00\end{array}$ & $\begin{array}{l}6,09 \\
6,33 \\
5,83 \\
0,00\end{array}$ & $\begin{array}{r}1,46 \\
1,24 \\
11,84 \\
0,00\end{array}$ & $\begin{array}{r}41,52 \\
19,71 \\
1,74 \\
0,00\end{array}$ & $\begin{array}{l}0,374 \\
0,154 \\
0,170 \\
0,000\end{array}$ & $\begin{array}{l}50 \\
75 \\
1,40 \\
0,00\end{array}$ & $\begin{array}{l}\text { mal } \\
\text { bom } \\
\text { bom }\end{array}$ & $\begin{array}{l}\text { Muito alta } \\
\text { Muito alta } \\
\text { Muito alta } \\
\text { Muito alto }\end{array}$ & $\begin{array}{c}23 \\
27 \\
27 \\
0,00\end{array}$ \\
\hline$\overline{\mathrm{A3}}$ & $\begin{array}{l}\mathrm{AP} \\
\mathrm{AB} \\
\mathrm{BO} 1 \\
\mathrm{BO} 2\end{array}$ & 6 & $\begin{array}{l}22,28 \\
29,13 \\
35,82 \\
43,75\end{array}$ & $\begin{array}{l}18,63 \\
33,33 \\
38,53 \\
41,87\end{array}$ & $\begin{array}{r}32,88 \\
4,71 \\
6,10 \\
10,16\end{array}$ & $\begin{array}{l}1,28 \\
3,39 \\
2,74 \\
2,13\end{array}$ & $\begin{array}{r}24,93 \\
29,44 \\
16,81 \\
2,09\end{array}$ & $\begin{array}{l}0,325 \\
0,288 \\
0,211 \\
0,150\end{array}$ & \begin{tabular}{|l|}
1,10 \\
71 \\
90 \\
12
\end{tabular} & $\begin{array}{l}\text { bom } \\
\text { boin } \\
\text { boin } \\
\text { bom }\end{array}$ & $\begin{array}{l}\text { Alta } \\
\text { Muito alta } \\
\text { Muito alta } \\
\text { Muito alta }\end{array}$ & $\begin{array}{l}21 \\
29 \\
29 \\
28\end{array}$ \\
\hline$\overline{\text { AJ } 4}$ & $\begin{array}{l}\mathrm{Ap} \\
\mathrm{AB} \\
\mathrm{BA} \\
\mathrm{BOI} \\
\mathrm{BO} 2\end{array}$ & 2,5 & $\begin{array}{l}28,75 \\
23,91 \\
35,82 \\
30,96 \\
5 t, 01\end{array}$ & $\begin{array}{l}33,38 \\
35,78 \\
38,53 \\
32,16 \\
43,13\end{array}$ & $\begin{array}{r}13,80 \\
11,68 \\
6,10 \\
11,35 \\
4,97\end{array}$ & $\begin{array}{l}3,66 \\
5,88 \\
2,74 \\
3,93 \\
0,89\end{array}$ & $\begin{array}{c}20,41 \\
22,75 \\
16,81 \\
21,60 \\
0,0\end{array}$ & $\begin{array}{l}0,226 \\
0,282 \\
0,212 \\
0,255 \\
0,129\end{array}$ & $\begin{array}{l}1,00 \\
1,10 \\
90 \\
90 \\
96\end{array}$ & $\begin{array}{l}\text { bom } \\
\text { bom } \\
\text { bom } \\
\text { bom } \\
\text { bom }\end{array}$ & $\begin{array}{l}\text { Muito alta } \\
\text { Muito alta } \\
\text { Muito alta } \\
\text { Muito alta } \\
\text { Muito alta }\end{array}$ & $\begin{array}{l}21 \\
25 \\
29 \\
27 \\
28\end{array}$ \\
\hline$\overline{\mathrm{AJ} 5}$ & $\begin{array}{l}\mathrm{AP} \\
\mathrm{BA} \\
\mathrm{BO} 1 \\
\mathrm{BO} 2 \\
\mathrm{BO} 3\end{array}$ & 0 & $\begin{array}{l}17,89 \\
26,53 \\
26,93 \\
37,31 \\
39,43\end{array}$ & $\begin{array}{l}20,58 \\
31,39 \\
31,91 \\
37,85 \\
39,52\end{array}$ & $\begin{array}{r}9,60 \\
19,53 \\
18,42 \\
14,69 \\
12,98\end{array}$ & $\begin{array}{l}3,81 \\
9,08 \\
6,35 \\
4,20 \\
4,21\end{array}$ & $\begin{array}{r}48,12 \\
13,47 \\
16,39 \\
5,95 \\
3,86\end{array}$ & $\begin{array}{l}0,478 \\
0,252 \\
0,255 \\
0,181 \\
0,169\end{array}$ & \begin{tabular}{|l|}
51 \\
1,50 \\
1,30 \\
1,30 \\
1,30
\end{tabular} & $\begin{array}{l}\text { mal } \\
\text { muito bom } \\
\text { muito bom } \\
\text { muito bom } \\
\text { muito bom }\end{array}$ & $\begin{array}{l}\text { Mediana } \\
\text { Muito alta } \\
\text { Muito alta } \\
\text { Muito alta } \\
\text { Muito alta }\end{array}$ & $\begin{array}{l}20 \\
21 \\
23 \\
25 \\
26\end{array}$ \\
\hline
\end{tabular}

Tabela 5 - Características químicas dos perfis (AJ 1 a AJ5)

Table 5 - Chemical characteristics of the profiles (AJ l a AJ5)

\begin{tabular}{|c|c|c|c|c|c|c|c|c|c|c|c|c|c|c|c|c|}
\hline \multirow{2}{*}{$\begin{array}{c}\text { Manejo } \\
\text { en } \\
\text { ancos }\end{array}$} & \multirow{2}{*}{$\begin{array}{c}\text { Hori- } \\
\text { zon- } \\
\text { tos }\end{array}$} & \multirow{2}{*}{$\begin{array}{c}\mathrm{pH} \\
\mathrm{H}_{7} \mathrm{O}\end{array}$} & \multirow[b]{2}{*}{$\mathrm{KCl}$} & \multirow[b]{2}{*}{ pH } & \multirow[b]{2}{*}{$\mathrm{N}_{\mathrm{w}} \%$} & \multirow{2}{*}{$\begin{array}{c}\mathbf{P} \\
\mathbf{p p m}\end{array}$} & $\bar{K}$ & $\mathrm{Ca}$ & $\mathbf{M g}$ & $\mathrm{Na}$ & Al & $\mathbf{H}$ & $\mathbf{s}$ & $T$ & \multirow{2}{*}{$\begin{array}{l}Y \\
q\end{array}$} & \multirow{2}{*}{ Sat $\mathrm{A}$} \\
\hline & & & & & & & \multicolumn{8}{|c|}{ em $g / 100 \mathrm{~g}$} & & \\
\hline \multicolumn{17}{|c|}{$A J 1$} \\
\hline 17 & $\begin{array}{l}\mathrm{AP} \\
\mathrm{AB} \\
\mathrm{BO} 1 \\
\mathrm{BO} 2 \\
\mathrm{BO} 3\end{array}$ & $\begin{array}{l}7,19 \\
4,90 \\
4,41 \\
4,40 \\
4,70\end{array}$ & $\begin{array}{l}6,08 \\
3,89 \\
3,68 \\
3,75 \\
3,89\end{array}$ & $\begin{array}{l}-1,10 \\
-1,00 \\
-0,73 \\
-0,65 \\
-0,85\end{array}$ & $\begin{array}{c}0,31 \\
\vdots \\
\vdots \\
\end{array}$ & $\begin{array}{r}94,00 \\
2,51 \\
0,63 \\
0,37 \\
0,37\end{array}$ & $\begin{array}{l}1,63 \\
0,05 \\
0,05 \\
0,04 \\
0,03\end{array}$ & $\begin{array}{l}2,96 \\
0,69 \\
0,27 \\
0,24 \\
0,42\end{array}$ & $\begin{array}{l}0,98 \\
0,26 \\
0,10 \\
0,14 \\
0,22\end{array}$ & $\begin{array}{l}0,60 \\
0,00 \\
0,00 \\
0,00 \\
0,00\end{array}$ & $\begin{array}{l}0,08 \\
0,46 \\
0,88 \\
0,83 \\
0,51\end{array}$ & $\begin{array}{l}1,09 \\
2,03 \\
2,06 \\
1,84 \\
1,62\end{array}$ & $\begin{array}{l}6,17 \\
1,00 \\
0,42 \\
0,42 \\
0,66\end{array}$ & $\begin{array}{l}7,34 \\
3,49 \\
3,36 \\
3,09 \\
2,80\end{array}$ & $\begin{array}{l}84 \\
29 \\
13 \\
13 \\
24\end{array}$ & $\begin{array}{r}1,0 \\
12,0 \\
20,0 \\
21,0 \\
15,0\end{array}$ \\
\hline \multicolumn{17}{|c|}{$\overline{\mathrm{AJ}} 2$} \\
\hline 13 & $\begin{array}{l}\text { A9 } \\
\mathrm{BO} 1 \\
\mathrm{BO2} \\
\mathrm{BO3}\end{array}$ & $\begin{array}{l}6,28 \\
4,28 \\
4,95 \\
4,48\end{array}$ & $\begin{array}{l}5,20 \\
3,65 \\
3,90 \\
3,71\end{array}$ & $\begin{array}{l}-1,03 \\
-0,63 \\
-1,05 \\
-0,77\end{array}$ & $\begin{array}{c}0,29 \\
= \\
=\end{array}$ & $\begin{array}{r}65,50 \\
0,72 \\
0,46 \\
0,72\end{array}$ & $\begin{array}{l}0,20 \\
0,01 \\
0,02 \\
0,03\end{array}$ & $\begin{array}{l}3,38 \\
0,22 \\
0,24 \\
0,37\end{array}$ & $\begin{array}{l}0,70 \\
0,06 \\
0,08 \\
0,13\end{array}$ & $\begin{array}{l}0,10 \\
0,00 \\
0,00 \\
0,00\end{array}$ & $\begin{array}{l}0,11 \\
0,98 \\
0,90 \\
0,45\end{array}$ & $\begin{array}{l}1,84 \\
2,21 \\
1,81 \\
1,76\end{array}$ & $\begin{array}{l}4,38 \\
0,29 \\
0,34 \\
0,53\end{array}$ & $\begin{array}{l}6,33 \\
3,48 \\
3,05 \\
2,74\end{array}$ & $\begin{array}{c}69 \\
8,4 \\
11,15 \\
19,20\end{array}$ & $\begin{array}{r}2,0 \\
22,0 \\
23,0 \\
14,0\end{array}$ \\
\hline \multicolumn{17}{|c|}{ AJ 3} \\
\hline$\overline{6}$ & $\begin{array}{l}\mathrm{AP} \\
\mathrm{AB} \\
\mathrm{BO} 1 \\
\mathrm{BO2}\end{array}$ & $\begin{array}{l}6,90 \\
4,70 \\
4,30 \\
4,76\end{array}$ & $\begin{array}{l}5,29 \\
3,78 \\
3,73 \\
3,86\end{array}$ & $\begin{array}{l}-1,61 \\
-0,92 \\
-0,57 \\
-0,90\end{array}$ & $\begin{array}{c}0,26 \\
\vdots \\
=\end{array}$ & $\begin{array}{r}48,36 \\
0,85 \\
0,59 \\
0,46\end{array}$ & $\begin{array}{l}0,47 \\
0,06 \\
0,07 \\
0,15\end{array}$ & $\begin{array}{l}3,94 \\
0,32 \\
0,16 \\
0,32\end{array}$ & $\begin{array}{l}1,04 \\
0,18 \\
0,11 \\
0,19\end{array}$ & $\begin{array}{l}0,17 \\
0,00 \\
0,00 \\
0,00\end{array}$ & $\begin{array}{l}0,13 \\
0,96 \\
0,96 \\
0,59\end{array}$ & $\begin{array}{l}0,66 \\
3,20 \\
2,58 \\
1,81\end{array}$ & $\begin{array}{l}5,62 \\
0,56 \\
0,34 \\
0,66\end{array}$ & $\begin{array}{l}6,41 \\
4,72 \\
3,88 \\
3,06\end{array}$ & $\begin{array}{r}88 \\
11,90 \\
8,70 \\
21,70\end{array}$ & $\begin{array}{r}2,0 \\
17,0 \\
20,0 \\
16,0\end{array}$ \\
\hline \multicolumn{17}{|c|}{ AJ 4} \\
\hline & $\begin{array}{l}\mathrm{AP} \\
\mathrm{AB} \\
\mathrm{BA} \\
\mathrm{BO} 1 \\
\mathrm{BO} 2\end{array}$ & $\begin{array}{l}5,06 \\
4,33 \\
4,34 \\
4,46 \\
4,80\end{array}$ & $\begin{array}{l}3,85 \\
3,72 \\
3,67 \\
3,69 \\
3,86\end{array}$ & $\begin{array}{l}-1,21 \\
-0,61 \\
-0,67 \\
-0,77 \\
-0,94\end{array}$ & $\begin{array}{c}0,14 \\
\vdots \\
\vdots \\
\vdots\end{array}$ & $\begin{array}{r}20,20 \\
0,83 \\
0,63 \\
0,57 \\
0,50\end{array}$ & $\begin{array}{l}0,23 \\
0,03 \\
0,03 \\
0,03 \\
0,02\end{array}$ & $\begin{array}{l}0,59 \\
0,24 \\
0,21 \\
0,18 \\
0,18\end{array}$ & $\begin{array}{l}0,18 \\
0,13 \\
0,03 \\
0,03 \\
0,03\end{array}$ & $\begin{array}{l}0,06 \\
0,00 \\
0,00 \\
0,00 \\
0,00\end{array}$ & $\begin{array}{l}0,54 \\
0,98 \\
1,07 \\
0,83 \\
0,74\end{array}$ & $\begin{array}{l}2,69 \\
3,33 \\
3,12 \\
2,06 \\
2,00\end{array}$ & $\begin{array}{l}1,06 \\
0,40 \\
0,27 \\
0,22 \\
0,22\end{array}$ & $\begin{array}{l}4,29 \\
4,71 \\
4,46 \\
3,18 \\
3,00\end{array}$ & $\begin{array}{c}24,75 \\
8,5 \\
6,06 \\
7,47 \\
7,90\end{array}$ & $\begin{array}{l}11,0 \\
17,0 \\
19,0 \\
22,0 \\
20,0\end{array}$ \\
\hline \multicolumn{17}{|c|}{$\mathrm{AJ}_{5}$} \\
\hline$\overline{0}$ & $\begin{array}{l}\mathrm{AP} \\
\mathrm{BA} \\
\mathrm{BO1} \\
\mathrm{BO2} \\
\mathrm{BO3}\end{array}$ & $\begin{array}{l}5,00 \\
4,35 \\
4,60 \\
4,35 \\
4,33\end{array}$ & $\begin{array}{l}3,85 \\
3,96 \\
4,06 \\
4,20 \\
4,25\end{array}$ & $\begin{array}{l}-1,15 \\
-0,39 \\
-0,54 \\
-0,35 \\
-0,08\end{array}$ & $\begin{array}{c}0,06 \\
: \\
\vdots\end{array}$ & $\begin{array}{r}13,54 \\
2,90 \\
1,66 \\
0,41 \\
0,00\end{array}$ & $\begin{array}{l}0,18 \\
0,04 \\
0,04 \\
0,03 \\
0,02\end{array}$ & $\begin{array}{l}0,48 \\
0,18 \\
0,21 \\
0,21 \\
0,21\end{array}$ & $\begin{array}{l}0,24 \\
0,06 \\
0,05 \\
0,06 \\
0,05\end{array}$ & $\begin{array}{l}0,06 \\
0,11 \\
0,10 \\
0,10 \\
0,10\end{array}$ & $\begin{array}{l}0,66 \\
0,70 \\
0,51 \\
0,30 \\
0,24\end{array}$ & $\begin{array}{l}2,46 \\
2,27 \\
1,73 \\
3,52 \\
1,46\end{array}$ & $\begin{array}{l}0,96 \\
0,39 \\
0,40 \\
0,40 \\
0,38\end{array}$ & $\begin{array}{l}4,08 \\
3,36 \\
2,64 \\
2,22 \\
2,07\end{array}$ & $\begin{array}{l}23,55 \\
11,61 \\
15,15 \\
18,02 \\
18,36\end{array}$ & $\begin{array}{l}14,0 \\
17,0 \\
16,0 \\
12,0 \\
10,0\end{array}$ \\
\hline
\end{tabular}


Tabela 6 - Caracterização da matéria química orgânica do solo

Table 6 - Organic chemical matter characterization of soil

\begin{tabular}{|c|c|c|c|c|c|c|c|c|c|c|c|c|}
\hline $\begin{array}{l}\text { Perfily } \\
\text { Idade }\end{array}$ & $\begin{array}{l}\text { Hori- } \\
\text { zontes }\end{array}$ & $\begin{array}{l}\text { Declivi- } \\
\text { dade }\end{array}$ & $\begin{array}{l}\text { Profun- } \\
\text { didade }\end{array}$ & $\begin{array}{c}\text { M.O. (\$) } \\
\text { nufla }\end{array}$ & $\begin{array}{l}\text { M.O. } \\
\text { (\%) }\end{array}$ & $\underset{(\%)}{C .0 \mathrm{~g} .}$ & $\begin{array}{c}\text { C. Ext. } \\
\text { (\$) }\end{array}$ & Huminas & $\begin{array}{c}\text { Ac. } \\
\text { hómico }\end{array}$ & $\begin{array}{c}\text { Ac. } \\
\text { fúlvico }\end{array}$ & $\begin{array}{l}\text { Relagyato } \\
\text { AF/AH }\end{array}$ & $\begin{array}{c}\text { Relacialo } \\
\text { CNN }\end{array}$ \\
\hline $\begin{array}{l}\overline{A J 1} \\
17 \text { anos }\end{array}$ & $\mathbf{A p}$ & $\overline{1-28}$ & $0.23 \mathrm{~cm}$ & 3,8740 & 6,2574 & 3,6296 & 5,5642 & 1,9343 & 3,0603 & 3,3532 & 1,0957 & 11,599 \\
\hline $\begin{array}{l}\mathrm{AJ} 2 \\
13 \text { anos }\end{array}$ & $A_{p}$ & $1-2 \%$ & $0-20 \mathrm{~cm}$ & 5.2960 & 5,7332 & 3,3255 & 3,4980 & 0,1725 & 2,7173 & 3,4980 & 1,2873 & 11,603 \\
\hline $\begin{array}{l}\mathrm{AJ} 3 \\
6 \operatorname{anos}\end{array}$ & $A P$ & $1-2 \%$ & $0-16 \mathrm{~cm}$ & 5,2600 & 5,2479 & 3,0440 & 3,6701 & 0,6261 & 2,9754 & $3, \mathbf{3 0 7 7}$ & 1,1117 & 11,600 \\
\hline $\begin{array}{l}\text { AJ } 4 \\
2,5 \text { anos }\end{array}$ & $A p$ & $1.2 \%$ & $0.14 \mathrm{~cm}$ & 1,2140 & 2,8256 & 1,6390 & 4,6136 & 2,9746 & 2,6572 & 3,4602 & 1,3022 & 11,599 \\
\hline $\begin{array}{l}\text { A } 5 \\
0 \text { ano }\end{array}$ & $A P$ & $1-2 \%$ & $0.20 \mathrm{~cm}$ & 3.9640 & 1,2930 & 0,7500 & 4,6033 & 4,6033 & 2,9947 & 4,6160 & 1,5729 & 11,609 \\
\hline
\end{tabular}

tratado durante 2,5 anos, decaindo para 21,3 x 108 naquele tratado durante 6 anos. Houve variação menor para os fungos filamentosos e para actinomicetos (Tab. 8).

Não houve correlação estatisticamente significativa entre os números de bactérias, fungos filamentosos e actinomicetos e parâmetros tais como $\mathrm{pH}$, umidade, temperatura e matéria orgânica entre $5 \mathrm{~cm}$ e $20 \mathrm{~cm}$ de profundidade.

Tabela 7-Efeito pela amoreira e estrume de frango sobre a agregação do solo

Table 7 - Mulberry effect and by chicken manure on soil aggregation

\begin{tabular}{|c|c|c|c|c|c|}
\hline \multirow[t]{2}{*}{ Cultivo } & \multirow{2}{*}{$\begin{array}{l}\text { Tempo de } \\
\text { utilizaça }\end{array}$} & \multirow{2}{*}{$\begin{array}{c}\text { Co. } \\
\%\end{array}$} & \multicolumn{3}{|c|}{ Porcentagem dos agregados em ómido } \\
\hline & & & $2-0,25 \mathrm{~mm}$ & $<0,25$ & $>2,0$ \\
\hline Amoreira & 17 & 3,6 & 18,87 & 19,00 & 62,13 \\
\hline Alnoneirs: & 13 & 3,3 & 0,21 & 3,05 & 96,74 \\
\hline Amoreira & 6 & $\mathbf{3 , 0}$ & 2,71 & 11,70 & 85,59 \\
\hline Amoreira & 2,5 & 1,64 & 1,10 & 10,12 & 88,78 \\
\hline Cerrado & 0 & 0,75 & 4,15 & 10,06 & 85,88 \\
\hline
\end{tabular}

Nota-se que a matéria orgânica presente em aproximadamente $1,4 \%$ no testemunho vai incrementando com o tempo, até $7,2 \%$ aos 17 anos. Observa-se também que, este incremento de matéria orgânica repercute na degradação da estrutura, por promover agregados de tamanhos $>2 \mathrm{~mm}$, fato este que prejudica o volume de solo aproveitável pelas raízes das culturas (Malagón 1976). Exceção a isto é o comportamento do tratamento após 17 anos, o qual mostra que $19 \%$ da estruturação é favorável ao desenvolvimento radicular de qualquer cultura, devido a diminuição de $20 \%$ dos agregados $>2 \mathrm{~mm}$, o que torna o solo mais adequado a exploração pelas raízes da cultura. É também evidente o poder exagerado da cimentação do solo, não só da cultura. O que não está de acordo ao pesquisador Bauer (1963) afirma que plantas de sistemas pivotantes provocam desagregação dos solos, o que foi confirmado neste estudo, onde a cultura de amoreira, ao penetrar no solo, propaga suas raízes além do horizonte cimentado pela matéria orgânica, especialmente pelo efeito dos ácidos fulvicos, o que mostra uma excessiva agregação das partículas do solo, chegando a prejudicar a implantação das culturas e podendo promover a erosão laminar.
Tabela 8 - Determinação da temperatura do solo e do número de microrganismos $/ g$ de solo seco nas diferentes parcelas da área em estudo

Table 8 - Soil temperature determination and microrganisms content/g in dry soil

\begin{tabular}{|c|c|c|c|c|c|c|}
\hline PARCEIAS & 1 & 2 & 3 & 4 & 5 & $\bar{F}$ \\
\hline $\begin{array}{l}\text { Temperatura do solo } \\
\text { a } 5 \mathrm{~cm} \text { de profundidade } \\
\text { e a } 50 \mathrm{ma} 20 \mathrm{~cm}\left({ }^{\circ} \mathrm{C}\right)\end{array}$ & $\begin{array}{l}38 \\
32\end{array}$ & $\begin{array}{l}35 \\
30\end{array}$ & $\begin{array}{l}31 \\
25\end{array}$ & $\begin{array}{l}36 \\
29\end{array}$ & $\begin{array}{l}34 \\
27\end{array}$ & $\cdots$ \\
\hline $\begin{array}{l}\text { Número total de bac- } \\
\text { trias/g de solo pe- } \\
\text { so seco }\left(x 10^{\circ}\right)\end{array}$ & 35,8 & 17,7 & 6,0 & 18,1 & 4,3 & 0,61 n.s. \\
\hline $\begin{array}{l}\text { Nímero cotal de fun- } \\
\text { gos'g de solo peso } \\
\text { seco }\left(x 10^{7}\right)\end{array}$ & 25,7 & 20,1 & 22,8 & 23,9 & 19,7 & 0,87 n.s. \\
\hline $\begin{array}{l}\text { Número total de acti- } \\
\text { nomicetos/g de golo } \\
\left.\text { peso seco ( } 10^{9}\right)\end{array}$ & 2,5 & 3,3 & 5,0 & 3,3 & 2,5 & 0,30 n.s. \\
\hline
\end{tabular}

$1=$ Controle; 2 = Aplicação do estéreo durante dois anos; 3 = Aplicação do estéreo durante 6 anos; 4 = Aplicação do estéreo durante 13 anos e $5=$ Aplicação do estéreo durante 17 anos

CONCLUSÕES 1. Os valores das médias geométricas se apresentam entre 0,3 e 1,3 $\mathrm{mm}$; entretanto predominam os diâmetros próximos de $0,6 \mathrm{~mm}$; é dizer que, em condições atuais a maioria dos solos não apresenta degradação, manifestam forte tendência a ela.

2. As relações entre a média geométrica dos agregados e a dos $\mathrm{AF} / \mathrm{AH}$ não mostram uma correlação definida. Entretanto, medida que a relação AF/AH é maior que, 1 existe uma tendência a uma maior cimentação, resultando em $>$ porcentagem de agregados $<2 \mathrm{~mm}$.

3. Em qual apresenta-se um equilíbrio entre os agregados ótimos para o desenvolvimento das culturas $(0,25-2 \mathrm{~mm}) \mathrm{e} \mathrm{a}$ perda da agregação com agregados $<0,25 \mathrm{~mm}$. demonstrou-se com isto a mediana estabilidade estrutural dos diversos tratamentos.

4. Os valores da média geométrica dos agregados se apresentam entre 0,0 e $0,6 \mathrm{~mm}$; entretanto, predominam os diâmetros próximos de $0,3 \mathrm{~mm}$; é dizer que, em condições atuais, todos os solos apresentam degradação forte ou muito alta. 
5. As relações entre a média geométrica dos agregados e a dos $\mathrm{AF} / \mathrm{AH}$ não mostra boa correlação.

6. Em geral, apresenta-se em equilíbrio entre agregados ótimos para o desenvolvimento das culturas 0,25 a $2 \mathrm{~mm}$, e as proporções dos agregados que demonstram degradação estrutural, caso dos de diâmetro $<0,25 \mathrm{~mm}$, demonstrando com isto uma instabilidade muito alta.

a. A aplicação do estrume de frango em solos de baixa fertilidade atual e potencial traz como resultado um incremento da primeira.

b.Os incrementos em conteúdos de matéria orgânica para este tipo de solo (Latossolo Vermelho-Amarelo, textura média arenosa) são benéficos para a exploração agrícola posterior.

c. Os incrementos em fósforo, cálcio, potássio e magnésio serão de grande importância na agricultura. d. Correção da acidez do solo, devido possivelmente ao carbonato de cálcio, que é aplicado na cama da criação das aves e que portanto já vem incorporado neste tipo de resíduo orgânico. e. Os tipos de componentes desta matéria orgânica são muito ativos, podendo acarretar mudanças nas propriedades físicas (como estrutura, desenvolvimento da mesma e cor), físicoquímicas, como troca catiônica, soma de bases e saturação do meio.

f. De acordo com a literatura, deve-se aplicar serragem em mistura com o estrume de frango, com o fim de melhorar seu poder agregante.

g. Comprovadamente o estrume de frango é o melhor beneficiador do solo em formas de fósforo, facilmente assimiláveis pelas plantas.

\section{REFERÊNCIAS BIBLIOGRÁFICAS}

ALMEIDA, M.T. 1983. Decomposição da Vinhaça Incorporada ao Solo (Evolução de CO j e Formação de Biomassa Microbiana) e Destino da Complementação Nitrogenada. Piracicaba. 75 p. (Dissertação de Mestrado, ESALQ).

ANGULO, RJ.; ROLOFF, G.; SOUZA, L.P. 1984. Correlação entre diferentes formas de determinação e representação da estabilidade e resistência dos agregados do solo. Rev. Bras. Ciên. Solo, 8(1):7-12.

BAUER, L.D. 1963. Soil Physis. 3 ed. New York, Wiley and Sons. 489 p.

CAMARGO, M.N.; KLANT, E.; KAUFMAN, H.H. 1987. Classificação de solos usada em levantamentos pedológicos no Brasil. Rev. Bras. Ciên. Solo, 12(1): 11-33.

CENTURION, J.F. \& DEMATTÊ, J.L.1.1985. Efeitos de preparo nas propriedades físicas de um solo sob cerrado cultivado com soja. Rev. Bras. Ciên. Solo, 9(3):263-266.

CINTRA, F.L.D. \& MffiLNICZUK, J. 1983. Potencial de algumas espécies vegetais para a recuperação de solos com propriedades físicas degradadas. Rev. Bras. Ciên. Solo, 7(2):197-201.

EMPRESA BRASILEIRA DE PESQUISA AGROPECUÁRIA 1979. Manual de Métodos de Análises de Solos. Rio de Janeiro, EMBRAPA/Serv. Nac. Lev. Cons. Solos.

EMPRESA BRASILEIRA DE PESQUISA AGROPECUÁRIA 1988. Sistema Brasileiro de Classificação de Solos. $3^{*}$ aproximação. Rio de Janeiro, EMBRAPA/Serv. Nac. Lev. Cons. Solos. 122 p.

GARAVITO, N.F. 1979. Propriedades Químicas de los Suelos. Bogotá, Instituto Geográfico Agustin Codazzi/Subdirección Agrológica. 321 p.

GOMES, A.S.; PATELLA, J.F.; PAULLETTO, E.A. 1978. Efeitos de sistemas e tempo de cultivo sobre a estrutura de um solo podzólico vermelhoamarelo. Rev. Bras. Ciên. Solo, 2(1):17-21.

GOOSEN, D. 1971. Physiography and Soils of Llanos Orientales. Colombia, Publ. me. Enschede the Netherlands. 199 p.

HENIN, S.; GRAS, R; MONNIER, G. 1976. Os Solos Agrícolas. São Paulo, EDUSP. 327 p.

INSTITUTO DE PESQUISAS TECNOLÓGICAS DO ESTADO DE SÃO PAULO 1981. Mapa Geomorfológico do Estado de São Paulo: escala 1:1.000.000. São Paulo, IPT/DMGA.

JIMENEZ, J.R.R.; CORTÊS, L.A.; MALAGON, E.C.D. 1976. Caracierización y Manejo de Suelos Amazônicos. Bogotá, IGAC-UJTL.

JORGE.J.A. 1983.SoloManejoeAdubação. SãoPaulo,LivrariaNobel.309p.

KAÚRICHEV, I.S. 1984. Prácticas de Edafologia. Rússia, Editorial Mir. $280 \mathrm{p}$.

KIEHL, EJ. 1985. Fertilizantes Orgânicos. São Paulo, Editora Agronômica Ceres Ltda. $492 \mathrm{p}$

LEMOS, R.C. \& SANTOS, R.D. 1982. Manual de Descrição e Coleta de Solos no Campo. Campinas, Soe. Brás. Ciência do Solo. $45 \mathrm{p}$

MALAGON, D.C. 1976. Propriedades Físicas de los Suelos. Bogotá, Instituto Geográfico Agustin Codazzi/Subdirección Agrológica. $622 \mathrm{p}$. $\left(\right.$ Vol.Xn, n $\left.{ }^{\circ} 7\right)$.
McLEAN, R.C. \& COOK, W.R.C. 1968. Practical Field Ecology; a Guide for the Botany Departments of Universities, Colleges and Schools. London, George Allen \& Unncig. 215 p.

MELLO, F.A.F.; SOBRINHO, B.M.O.C.; ARZOLLA, S.; SILVEIRA, R.I.; NETTO, A.C.; KIEHL, J.C. 1983. Fertilidade do Solo. São Paulo, Livraria Nobel. $400 \mathrm{p}$.

MONTENEGRO, H.G. \& MALAGON, D.C. 1990. Propriedades Físicas de los Suelos. Bogotá, Instituto Geográfico Agustin Codazzi/Subdirección Agrológica. $813 \mathrm{p}$

NUERNBERG, NJ.; STAMMEL, J.G.; CABEDA, M.S.V. 1986. Efeito de sucessão de culturas de adubação em características físicas de um solo da encosta basáltica sul-rio-grandense. Rev. Bras. Ciên. Solo, 10(3): $185-190$.

ORJUELA, B.H. 1988. El componente bioquímico en Ia productividad y fertilidad dei suelo. In: Fertilidade de Suelos Diagnóstico y Control. Bogotá, Sociedad Colombiana de Ia Ciência dei suelo. p. $109-149$.

ORLANDO, J, F; ZAMBELLO, R., Jr; AGUJARO; ROSSETTO, AJ. 1983. Efeito de Aplicação Prolongada de Vinhaça nas Propriedades Quimicas dos Solos com Cana-de-Açúcar. Estudo Exploratório. Piracicaba, STAB, $n^{\circ} 6$, p. 28-33.

PAULA, J.L. \& COELHO, M.A. 1982. Método para determinação da estabilidade de agregados em solos sódicos e salino-sódicos. Rev. Bras. Ciên. Solo, 6(3):155-160.

PRIMAVESI, A. 1980. O Manejo Ecológico do Solo. São Paulo, Livraria Nobel. $541 \mathrm{p}$.

SOUZA, A.P.; FREIRA, W.J.; CURI, PR. 1982. Preparo do solo com arado de discos e seu efeito sobre a estabilidade mecânica dos agregados de um latossolo roxo. Rev. Bras. Ciên. Solo, 6(1):53-57.

STACANTI, G.; NOGUEIRA, J.B.; VILAR, O.M. 1981. Ensaios de Laboratório em Mecânica dos Solos. São Carlos, Escola de Engenharia de São Carlos/USP.208p.

TAUK, S.M. 1990. Effects of cumulative doses of vinasse on soil microorganisms in cerrado. Pedobiologia, 34:69-75.

VIEIRA, L.S. \& VIEIRA, M.N.F. 1983. Manual de Morfologia e Classificacão de Solos. São Paulo, Editora Agronômica Ceres Ltda. 313 p.

WAMBEKE, V. A. 1974. Propriedades que influyen ei manejo de los oxisoles en esistemas de Sabana. In: Manejo de suelos en Ia America Tropical. Rehigh, North Carolina State University, p. 371-379.
MANUSCRITO A709 Recebido em 2 de dezembro de 1991 Revisão do autor em 26 de maio de 1992 Revisão aceitra em 5 de junho de 1993 